Revista Monografias Ambientais - REMOA v. 15, n.1, jan-abr. 2016, p.105-116 Revista do Centro de Ciências Naturais e Exatas - UFSM, Santa Maria

\title{
POTENCIAL DE APROVEITAMENTO DE ÁGUA DE CHUVA NA UNIVERSIDADE FEDERAL DO PARÁ - BELÉM/PA
}

\author{
Potential of Rainwater harvesting in the Federal University of Pará-Belém/PA
}

\author{
Thays Valente do Nascimento ${ }^{1}$, Lindemberg Lima Fernandes², \\ Gabriel Hiromite Yoshino ${ }^{3}$
}

\author{
${ }^{1}$ Acadêmica de Engenharia Sanitária e Ambiental, Bosista PIBIC, Universidade Federal do Pará, \\ Belém, PA, Brasil \\ ${ }^{2}$ Doutor, FAESA/ITEC, Universidade Federal do Pará, Belém, PA, Brasil \\ ${ }^{3}$ M.Sc., Universidade Federal do Pará, Belém, PA, Brasil
}

Resumo

O objetivo deste artigo é avaliar o potencial de aproveitamento de água de chuva na Universidade Federal do Pará (UFPA), assim como a economia de água potável a partir de seu uso, contribuindo para a gestão e o planejamento sustentável dos recursos hídricos da região. Para isso, foram levantadas as áreas dos prédios do Setor Básico e Profissional da UFPA. Uma série histórica de precipitação com 46 anos de observações para o município de Belém foi utilizada. Foi realizado o monitoramento do consumo de água nos principais banheiros coletivos e estimados nos demais prédios. Os resultados mostram que devido ao alto índice pluviométrico e as grandes áreas de captação, a UFPA possui um potencial real e favorável de aproveitamento de água de chuva como forma alternativa de abastecimento, uma vez que verificou-se que nos meses chuvosos a economia de água potável pelo uso de água de chuva disponível, apresentou porcentagens superiores a 100\%, o que demostra uma ótima alternativa para a economia de água fornecida pelo sistema de abastecimento da universidade.

Palavras-chave: Aproveitamento de água de chuva. Recursos hídricos. Economia de água potável. Belém.

\section{Abstract}

The objective of this article is to evaluate the potential of rainwater harvesting in the Federal University of Pará (UFPA), as well as the potable water savings by using rainwater, contributing to the management and sustainable resource planning water in the region. For this, the areas of the buildings of Basic and Professional Sector of university were raised. A time series of rainfall with 46 years of observations to the city of Belém was used. Water consumption in the two colletive bathrooms was monitored and was estimated in other buildings. The results show that due to high rainfall and large catchment areas, the UFPa has a real and positive potential for rainwater utilization as an alternative supply, since it was found that in the rainy season economics drinking water by rainwater use presented percentages greater than 100\%, which demonstrates a great alternative to water savings provided by the university's supply system

Keywords: Rainwater harvesting, water resources, potable water savings, Belém. 


\section{INTRODUÇÃO}

A água é um elemento essencial para a manutenção da vida dos seres vivos e possui diversos usos, contribuindo para o desenvolvimento econômico e tecnológico mundial. O pensamento de que este recurso natural é inesgotável, ainda justifica o uso irracional em muitas localidades, o que pode prejudicar a disponibilidade deste bem para as atuais e futuras gerações.

O crescimento populacional, a poluição ambiental e o uso não racional da água têm levado ao aumento da demanda de água potável, o que vêm reduzindo gradativamente a disponibilidade e a qualidade deste recurso em termos mundiais.

A distribuição dos recursos hídricos relacionados à concentração populacional é outro fator preocupante em relação à disponibilidade de água potável. Os locais mais populosos são justamente os que possuem pouca água, por outro lado onde há muita água ocorre baixo índice populacional. Por exemplo, a Região Sudeste do Brasil, que dispõe de um potencial hídrico de apenas $6 \%$ do total nacional, conta com $43 \%$ do total de habitantes do país, enquanto a Região Norte, que compreende a Bacia Amazônica, apresenta $69 \%$ de água disponível, contando com apenas $8 \%$ da população brasileira (GHISI, 2006; COUTO, 2012).

Com isso, vários estudos estão sendo realizados com o objetivo de propor soluções alternativas para minimizar o consumo de água potável. Neste contexto, estudos sobre o aproveitamento de água de chuva para fins não potáveis estão expandindo-se cada vez mais, por se tratar de um recurso natural e bastante abundante na maioria das regiões brasileiras.

No setor residencial, Flores et al. (2012), analisaram o potencial de aproveitamento da água de chuva na cidade de Belém. Verificando que o atendimento com água da chuva poderia ocorrer no mínimo para $18 \%$ da população (cerca de 200 mil pessoas) e no máximo para cerca de $37 \%$ da população (cerca de 420 mil pessoas).

Estudo realizado por Lima et al. (2011) para avaliar o potencial de economia de água potável pelo uso de água de chuva na Amazônia, determinou que um potencial médio de economia de água de $76 \%$ nas cidades analisadas.

Em um estudo realizado em quatro cidades médias do estado de São Paulo por Ortiz et al. (2009), foi constatado a partir do uso de água de chuva um potencial médio mensal de economia de água potável de $39,4 \%$ variando desde $7 \%$ até $92,7 \%$.

Ainda em relação ao setor residencial, Ghisi et al. (2007) avaliaram o potencial de economia de água potável pelo uso de água de chuva em várias cidades da região sudeste do Brasil e, a partir dos resultados obtidos, observou-se que o potencial médio de economia de água no sudeste foi de $41 \%$.

Com relação ao consumo de água em instituições de ensino, é importante ressaltar que ele pode variar bastante devido aos tipos de aparelhos sanitários e às dependências existentes no local, como lanchonetes, ginásios, laboratórios, cozinha, horta e outros ambientes em que ocorre consumo de água (FASOLA et al., 2011).

Na Universidade Federal do Pará (UFPA), vários estudos têm sido realizados dentro desta temática. Yoshino (2012), propôs um sistema de aproveitamento de água de chuva para os dois banheiros coletivos do Setor Básico e Profissional; Conceição (2014) desenvolveu um projeto de sistema de aproveitamento de água de chuva para um prédio localizado no Campus Profissional da UFPA. Silva et al. (2013), avaliaram o potencial de aproveitamento de água de chuva em 57 edificações do Campus Básico da UFPA, no qual os resultados mostraram um potencial de uso da água de chuva positivo ao longo de todos os meses do ano, o que demonstra que podem ser abastecidas por água de chuva.

O objetivo deste artigo é apresentar o potencial de aproveitamento de água de chuva na UFPA, assim como o potencial de economia de água potável a partir do uso da água de chuva, contribuindo para a gestão e o planejamento sustentável dos recursos hídricos da região. 


\section{MATERIAL E MÉTODOS}

\section{1 Área de estudo}

A área em estudo está localizada na UFPA, a qual fica localizada no município de Belém-PA. A universidade divide-se em quatro setores, a saber: Setor Básico, Profissional, Saúde e Esportivo, conforme Figura 1. O foco da presente pesquisa foi o Setor Básico e o Profissional, sendo que os dois banheiros usados para o desenvolvimento deste trabalho, localiza-se um em cada Setor.

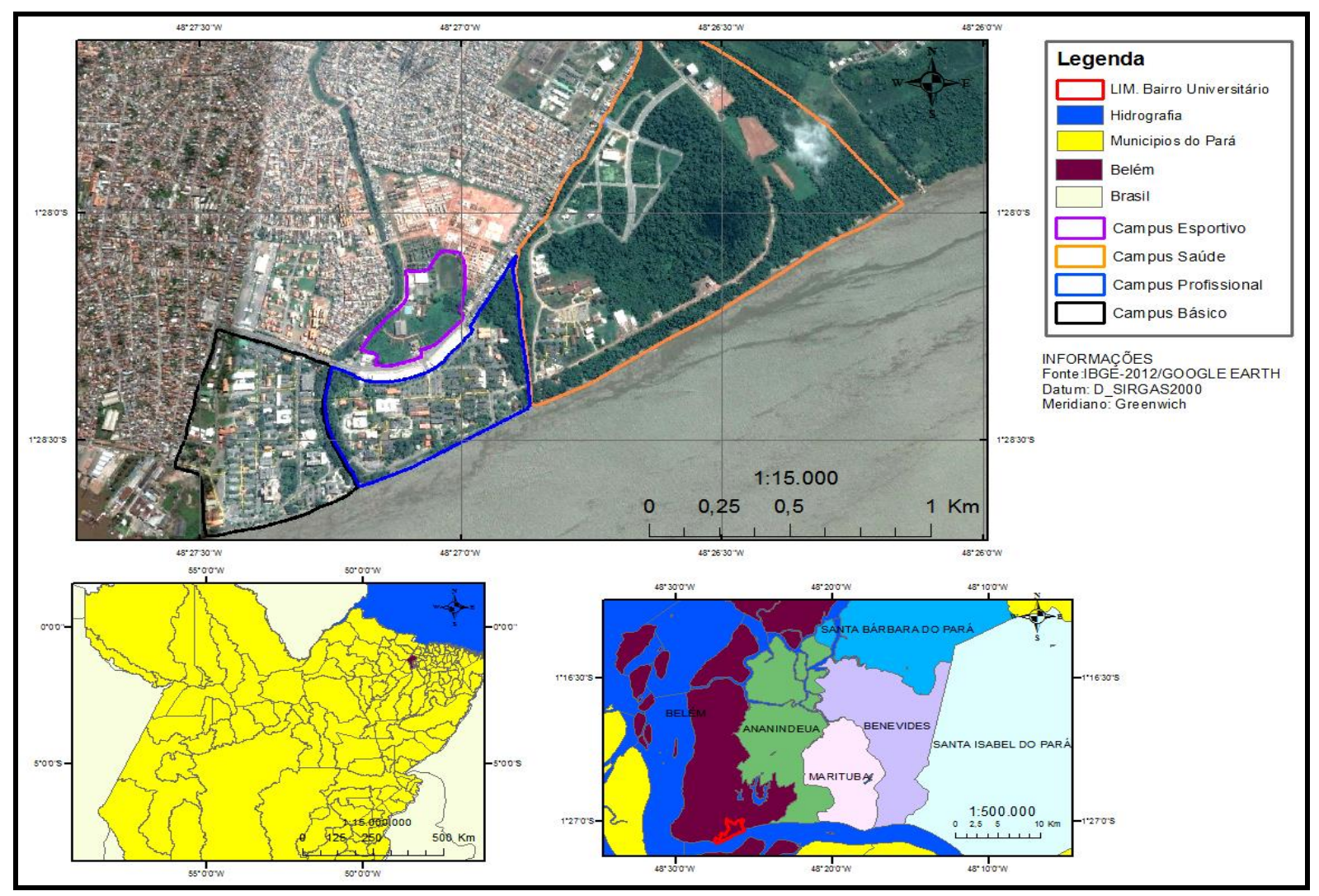

Figura 1 - Localização da Universidade Federal do Pará

Fonte: Autor (2014)

\subsection{Levantamento de dados e informações}

O levantamento das áreas de telhados foi realizado a partir da planta arquitetônica com dados de 2014. Para o cálculo do potencial de aproveitamento de água de chuva foi considerado a projeção dos telhados em planta para os diferentes tipos de telhados.

Para a realização desta pesquisa foram utilizados os dados do Instituto Nacional de Meteorologia (INMET), de chuvas mensais da cidade de Belém, disponíveis no Sistema de Informações Hidrológicas (HidroWeb) da Agência Nacional de Águas (ANA), referentes ao período de 1967 a 2013. Esta série histórica com 46 anos de observações foi utilizada para geração dos valores mínimos, médios e máximos da série temporal, além disso, foram calculados os percentis (com valores de 75, 85 e 95\%), de modo a fornecerem estimativas de probabilidades nos resultados gerados.

Tomaz (2003) salienta que, a precipitação média não oferece uma probabilidade confiável dos dados, já que é de aproximadamente 40\%. Assim, Vyas (1999, apud Tomaz, 2003) apresenta a probabilidade de $95 \%$ como extremamente confiável, a de $85 \%$ confiável e a de $75 \%$ tolerável. Desta forma, para a realização dos cálculos necessários neste estudo, foram adotados os dados pluviométricos de Belém com probabilidade de $85 \%$. 


\subsection{Consumo de água nos banheiros coletivos da UFPA}

Os banheiros pesquisados ficam situados próximos aos blocos de salas de aula e das praças de alimentação, o que justifica o fluxo contínuo de usuários e um consumo bastante representativo de água potável. Além disso, outro fator considerado para justificar o uso destes dois banheiros para o desenvolvimento deste estudo é o fato de serem hidrometrados.

Cada banheiro é dividido em compartimentos feminino e masculino. Os dois banheiros apresentam a mesma quantidade de aparelhos. Para obter a demanda de água nestes banheiros, foi realizado o monitoramento do consumo através da leitura diária dos hidrômetros instalados nos ramais de alimentação de cada banheiro.

O monitoramento do consumo foi realizado, no período de Setembro/2014 a Junho/2015, havendo uma defasagem de $1 \mathrm{~h}$ para leitura em cada hidrômetro devido à distância entre cada banheiro do Setor Profissional e do Básico .

\subsection{Estimativa do consumo teórico nos demais prédios}

Para estimar o consumo teórico de água dos demais prédios das áreas em estudo, os quais não são hidrometrados, foi realizado o levantamento quantitativo de aparelhos sanitários dos banheiros coletivos monitorados, aos quais foram atribuídos pesos de acordo com o método dos pesos relativos, recomendado pela NBR 5626/1998. A partir desta atribuição foi utilizado o método da raiz quadrada (Equação 1) para o cálculo da vazão nos banheiros. Estes procedimentos foram utilizados em estudos desenvolvidos por Sá (2012) no Setor Básico da UFPA.

$$
Q=0,3 \sqrt{\sum P}
$$

Em que:

$\mathrm{Q}$ - vazão estimada $(\mathrm{l} / \mathrm{s})$;

0,3 - vazão de referência;

$\Sigma \mathrm{P}$ - somatório dos pesos relativos atribuídos aos aparelhos sanitários.

Em seguida, pelo uso da Equação 2, foi estimado o consumo de água diário, considerando um período de utilização de $16 \mathrm{~h}$, sendo este utilizado, devido ao período de atividades na UFPA (geralmente começa às $7 \mathrm{~h}$ e encerra por volta das $22 \mathrm{~h}$ ) total nos aparelho foi utilizada

$$
C d=Q_{\text {prédio }} \cdot T
$$

Em que:

$\mathrm{Cd}$ - consumo diário de água $\left(\mathrm{m}^{3} / \mathrm{d}\right)$;

Q prédio - consumo teórico $\left(\mathrm{m}^{3} / \mathrm{h}\right)$;

$\mathrm{T}$ - tempo de utilização (h).

Como o tipo e as quantidades de aparelhos do banheiro do Básico são iguais ao do Profissional, os cálculos foram realizados apenas para o Setor Profissional, e estes foram considerados para o Setor Básico.

Uma análise comparativa foi realizada entre os dados monitorados e estimados nos banheiros coletivos pesquisados. Com isso, foi possível determinar um coeficiente de redução para ter uma estimativa de maior confiabilidade no consumo das demais edificações. Este coeficiente foi determinado pelo uso da Equação 3. 


$$
C r=\frac{C m}{C t}
$$

Em que:

$\mathrm{Cr}$ - Coeficiente de redução;

$\mathrm{Cm}$ - Consumo diário monitorado na micromedição $\left(\mathrm{m}^{3}\right)$;

$\mathrm{Ct}$ - Consumo diário teórico estimado $\left(\mathrm{m}^{3}\right)$.

O coeficiente médio de redução foi determinado pela média entre o coeficiente do Setor Básico e do Profissional

A partir de informações obtidas na Prefeitura da UFPA, e de posse das plantas baixas dos prédios, realizou-se o levantamento das quantidades de banheiros e dos aparelhos sanitários de cada prédio do Setor Básico e Profissional, sendo considerado para esta estimativa apenas as bacias sanitárias e os mictórios, e o uso de válvula de descarga nestes aparelhos. Posteriormente, as equações 1 e 2 foram utilizadas para determinar o consumo estimado em cada prédio e, em seguida, o coeficiente de redução médio foi aplicado a estes consumos, obtendo-se desta forma, o consumo de água teórico diário corrigido para cada edificação. Assim, com a soma dos consumos teóricos diários de todos os prédios foi estimada a demanda de água no Setor Básico e Profissional.

\subsection{Potencial de aproveitamento de água de chuva}

O aproveitamento de água de chuva se torna mais viável quando o consumo de água não potável é elevado, caso de indústrias, edifícios públicos, escolas, universidades e entre outros, acarretando uma economia significativa de água tratada. Outro fator que contribui são as áreas de captação geralmente grandes, que proporcionam um maior volume de água potencialmente coletável (HAGEMANN, 2009).

Para a determinação do volume de água de chuva que pode ser aproveitado pelas áreas de telhados dos prédios do Setor Básico e Profissional, foi utilizada a metodologia aplicada por (GHISI et al., 2007; LIMA et al., 2011). Assim, o volume de chuva aproveitado foi calculado através da Equação 4.

$$
V=\frac{P \cdot A \cdot C}{1000}
$$

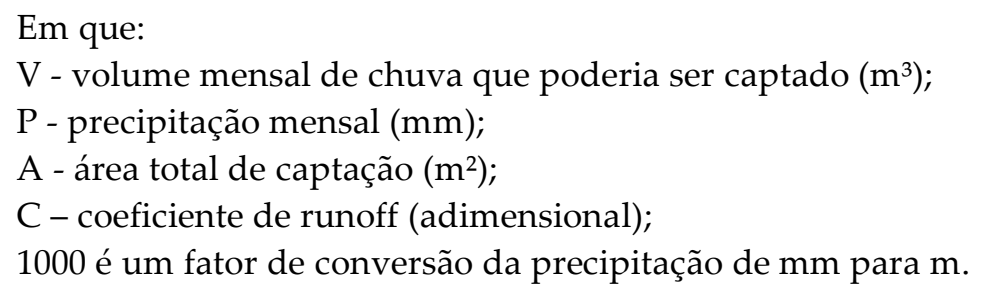

\subsection{Balanço hídrico e potencial de economia de água potável}

O potencial mensal de economia de água potável na UFPA foi determinado considerando os dados mensais do consumo de água (real + estimado) e do volume mensal de água de chuva captada, de acordo com a metodologia aplicada por (GHISI et al., 2007; LIMA et al., 2011), conforme Equação 5. 
$P E A P=\frac{V}{D A P} \times 100$

Em que:

PEAP - potencial de economia de água potável (\%);

$\mathrm{V}$ - Volume mensal de água chuva captada $\left(\mathrm{m}^{3}\right)$;

DAP - demanda mensal de água potável (estimado + real) $-\left(\mathrm{m}^{3}\right)$.

\section{RESULTADOS E DISCUSSÃO}

\subsection{Análise dos dados pluviométricos da cidade de Belém/PA}

A média anual para a série de dados estudada (1967 a 2013) foi de 3.029,0 $\mathrm{mm}$ de precipitação para a cidade de Belém (Tabela 2).

Tabela 2 - Dados estatísticos de precipitação em mm

\begin{tabular}{ccccccccccccc}
\hline \multirow{2}{*}{ TIPO } & \multicolumn{10}{c}{ MESES } \\
\cline { 2 - 11 } & JAN & FEV & MAR & ABR & MAI & JUN & JUL & AGO & SET & OUT & NOV & DEZ \\
\hline MÍNIMA & 181,6 & 230,8 & 232,5 & 212,1 & 110,8 & 2,8 & 29,0 & 52,3 & 28,1 & 8,2 & 17,8 & 40,9 \\
\hline MÉDIA & 377,5 & 408,9 & 443,1 & 404,3 & 301,0 & 179,2 & 158,7 & 134,5 & 130,2 & 121,6 & 125,4 & 247,5 \\
\hline MÁXIMA & 560,1 & 776,2 & 742,5 & 633,0 & 518,8 & 320,0 & 337,0 & 245,5 & 256,6 & 279,7 & 307,4 & 519,8 \\
\hline $\begin{array}{c}\text { PERCENTIL } \\
\text { 95\% }\end{array}$ & 220,3 & 249,5 & 246,0 & 224,5 & 137,9 & 67,5 & 59,7 & 58,9 & 52,9 & 20,6 & 37,6 & 92,4 \\
\hline $\begin{array}{c}\text { PERCENTIL } \\
\mathbf{8 5 \%}\end{array}$ & $\mathbf{2 7 9 , 7}$ & $\mathbf{3 3 1 , 1}$ & $\mathbf{3 3 1 , 3}$ & $\mathbf{2 9 0 , 0}$ & $\mathbf{1 9 7 , 3}$ & $\mathbf{1 0 0 , 0}$ & $\mathbf{9 6 , 4}$ & $\mathbf{7 6 , 5}$ & $\mathbf{8 9 , 3}$ & $\mathbf{5 8 , 4}$ & $\mathbf{6 0 , 6}$ & $\mathbf{1 4 4 , 4}$ \\
\hline $\begin{array}{c}\text { PERCENTIL } \\
\mathbf{7 5 \%}\end{array}$ & 331,8 & 351,6 & 382,9 & 334,6 & 225,1 & 123,3 & 108,9 & 92,7 & 92,5 & 82,9 & 79,0 & 175,9 \\
\hline
\end{tabular}

\section{2 Áreas de captação dos prédios}

As áreas de captação possuem dimensões variadas, uma vez que são edificações de vários tipos (blocos de salas de aula, laboratórios, prédios administrativos, restaurantes, etc). A maioria dos prédios possuem calhas e condutores verticais, o que facilitaria uma futura implantação de sistemas de aproveitamento de água de chuva.

De acordo com a análise da planta arquitetônica da UFPA, foram medidas as áreas de telhados de 85 edificações no Setor Básico, sendo a maior área de $3.922 \mathrm{~m}^{2}$ e a menor de $19,7 \mathrm{~m}^{2}$, totalizando uma área de cobertura de $57.292,5 \mathrm{~m}^{2}$. Para o Setor Profissional, foram medidas as áreas de 52 edificações, sendo a maior área de $1.637 \mathrm{~m}^{2} \mathrm{e}$ a menor de $85,2 \mathrm{~m}^{2}$, totalizando uma área de captação de $37.834,8 \mathrm{~m}^{2}$. 


\subsection{Consumo de água nos banheiros coletivos da UFPA}

Com os dados referentes ao monitoramento do consumo de água nos banheiros coletivos, foram analisados o consumo médio diário e o mensal. Os banheiros do Setor Básico e Profissional apresentaram um consumo médio diário de $5,21 \mathrm{~m}^{3}$ e $10,66 \mathrm{~m}^{3}$ respectivamente. Na Figura 2, observa-se a demanda de água mensal nestes banheiros, os quais foram semelhantes às pesquisas realizadas por (YOSHINO, 2012; PORTÉGLIO, 2012).

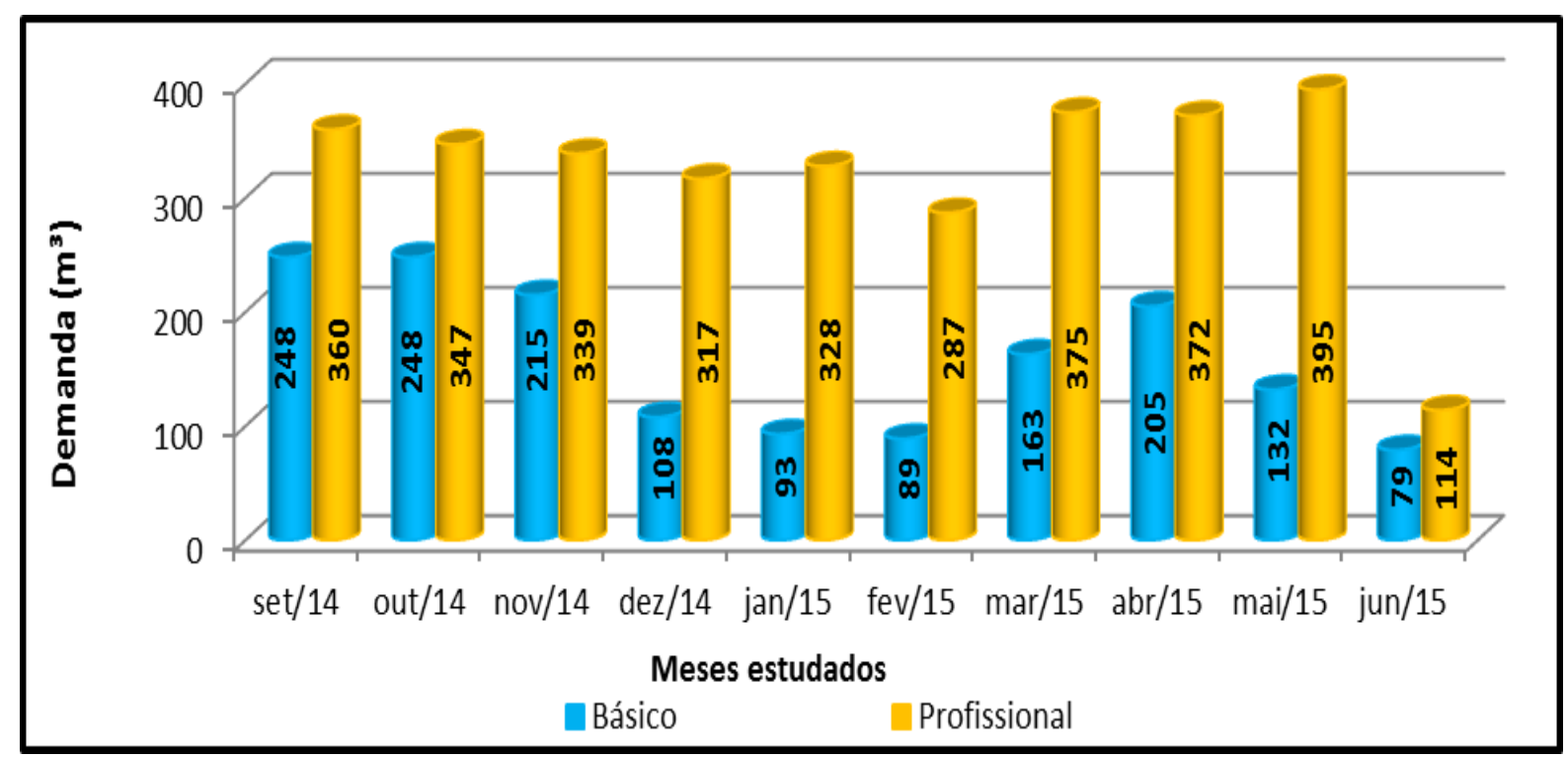

Figura 2 - Demanda de água mensal nos banheiros coletivos

Fonte: Autor (2015)

Pode-se observar que o consumo no banheiro coletivo situado no Setor Profissional, é superior ao consumo do banheiro no Básico. Isto porque no Setor Básico existem dois banheiros coletivos próximos às salas de aula e a praça de alimentação, o que faz com que o consumo seja dividido entre eles, por outro lado, no Profissional existe apenas um banheiro que concentra o consumo dos usuários da praça de alimentação e dos blocos de salas de aula.

No mês de Dezembro verifica-se uma menor demanda de água, devido ao início do período de recesso acadêmico. No mês de Junho o consumo foi menor ainda, refletindo o período de greve de professores e técnicos administrativos, que iniciou no final do mês de Maio/2015.

\subsection{Estimativa do Consumo de água nos demais prédios}

Como a maioria das edificações estudadas não possuem pontos de micromedição, o consumo de água nos banheiros foi estimado. Pelo método da raiz quadrada foram determinados os valores de vazão e o consumo diário teórico do banheiro do Setor Profissional, correspondendo a 10 bacias e 2 mictórios com válvula de descarga, 12 chuveiros e 8 lavatórios (Tabela 3).

Tabela 3 - Vazão e consumo médio teórico do banheiro do Setor Profissional

\begin{tabular}{c|c|c|c}
\hline Edificação & Vazão (Q) & $\begin{array}{c}\text { Tempo de } \\
\text { Utilização (T) }\end{array}$ & Consumo Diário \\
\hline $\begin{array}{c}\text { Banheiro (Setor } \\
\text { Profissional) }\end{array}$ & $\mathrm{m}^{3} / \mathrm{h}$ & $\mathrm{h}$ & $\mathrm{m}^{3}$ \\
\cline { 2 - 4 } & 19,70 & 16 & 315,24 \\
\hline
\end{tabular}


O consumo diário teórico para o banheiro do Setor Profissional foi de 315,24 $\mathrm{m}^{3}$, assim, este também foi o consumo teórico para o Setor Básico, uma vez que os dois possuem a mesma quantidade de aparelhos. Na Tabela 4 apresenta-se a comparação entre os dados estimados e monitorados dos banheiros e a determinação do coeficiente de redução de 0,0252 , e este foi aplicado nos cálculos do consumo teórico dos outros prédios.

Tabela 4 - Determinação do coeficiente de redução médio

\begin{tabular}{|l|c|c|c|c}
\hline Banheiro & $\begin{array}{c}\text { Consumo } \\
\text { Teórico } \\
\text { Diário }\left(\mathbf{m}^{\mathbf{3}}\right)\end{array}$ & $\begin{array}{c}\text { Consumo } \\
\text { Monitorado Médio } \\
\text { Diário }\left(\mathbf{m}^{\mathbf{3}}\right)\end{array}$ & $\begin{array}{c}\text { Coeficiente de Redução } \\
(\mathbf{C r})\end{array}$ & $\begin{array}{c}\text { Coeficiente de } \\
\text { Redução Médio }\end{array}$ \\
\hline Básico & 315,24 & 5,21 & 0,0165 & \multirow{2}{*}{0,0252} \\
\hline Profissional & 315,24 & 10,66 & 0,0338 & \\
\hline
\end{tabular}

A partir do levantamento dos equipamentos de água fria dos prédios, foram encontrados 489 bacias sanitárias e 91 mictórios no Setor Básico e 283 bacias sanitárias e 59 mictórios no Setor Profissional. Na Tabela 5 pode-se verificar a estimativa de consumo de água nas áreas estudadas.

Tabela 5 - Estimativa do consumo mensal de água

\begin{tabular}{c|c|c|c|c|c}
\hline \multirow{2}{*}{ Setor } & Vazão (Q) & $\begin{array}{c}\text { Tempo de } \\
\text { Utilização } \\
(\mathbf{T})\end{array}$ & $\begin{array}{c}\text { Coeficiente } \\
\text { de Redução } \\
(\mathbf{C r})\end{array}$ & $\begin{array}{c}\text { Consumo } \\
\text { Diário }\end{array}$ & $\begin{array}{c}\text { Consumo } \\
\text { Mensal }\end{array}$ \\
\cline { 2 - 4 } & $\mathrm{m}^{3} / \mathrm{h}$ & $\mathrm{H}$ & - & $\mathrm{m}^{3}$ & $\mathrm{~m}^{3}$ \\
\hline Básico & 956,69 & \multirow{2}{*}{16} & 0,0252 & 385,22 & $11.556,73$ \\
\hline Profissional & 562,64 & & & 226,55 & $6.796,60$ \\
\hline
\end{tabular}

\subsection{Potencial de aproveitamento de água de chuva}

Na Figura 3 são destacados os volumes mensais de água de chuva que poderiam ser captados pelos telhados das edificações do Setor Básico e do Profissional. O Setor Básico, por possuir um número de edificações superior ao do Profissional, apresentou potencial maior para aproveitamento de água de chuva.

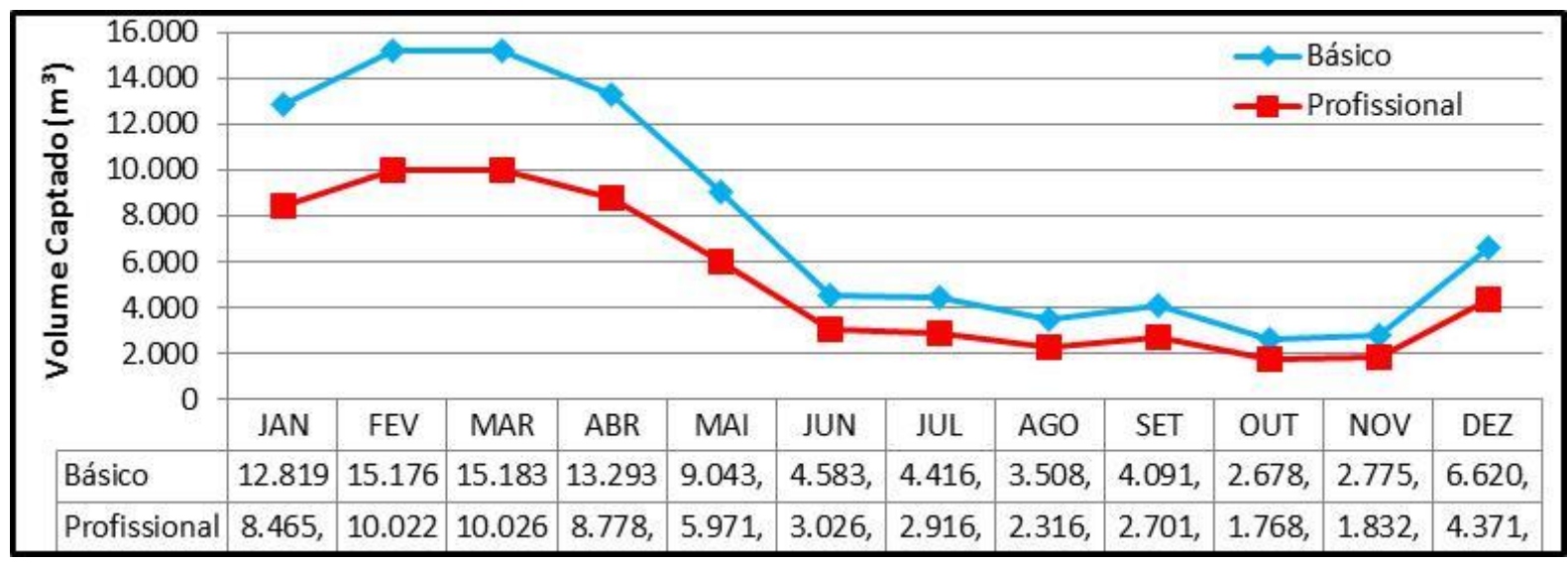

Figura 3 - Potencial de aproveitamento de água de chuva 
No período chuvoso, o potencial máximo do volume captado foi durante o mês de março, apresentando um total de $15.183 \mathrm{~m}^{3}$ e $10.026 \mathrm{~m}^{3}$ para os Setores Básico e Profissional respectivamente. No período menos chuvoso, o potencial mínimo de volume que pode ser captado foi obtido no mês de outubro, sendo possível captar um volume de $2.678 \mathrm{~m}^{3}$ e $1.768 \mathrm{~m}^{3}$ de água de chuva para os Setores Básico e Profissional, respectivamente. Nota-se, assim, que mesmo no período menos chuvoso, a quantidade de água de chuva que é possível captar ainda é consideravelmente alta, o que favorece a adoção de técnicas de aproveitamento de água de chuva nesta localidade. Vale destacar que é feito uma abordagem geral das áreas de telhados com uma probabilidade de ocorrência de precipitação, não se considerando o descarte, isto é, o volume não aproveitado, o que certamente superestima o potencial de captação.

\subsection{Balanço hídrico e economia de água potável}

Na Figura 4 e 5 mostra-se o balanço hídrico entre a demanda de água e o volume de água de chuva captado nos Setores Básico e Profissional, respectivamente.

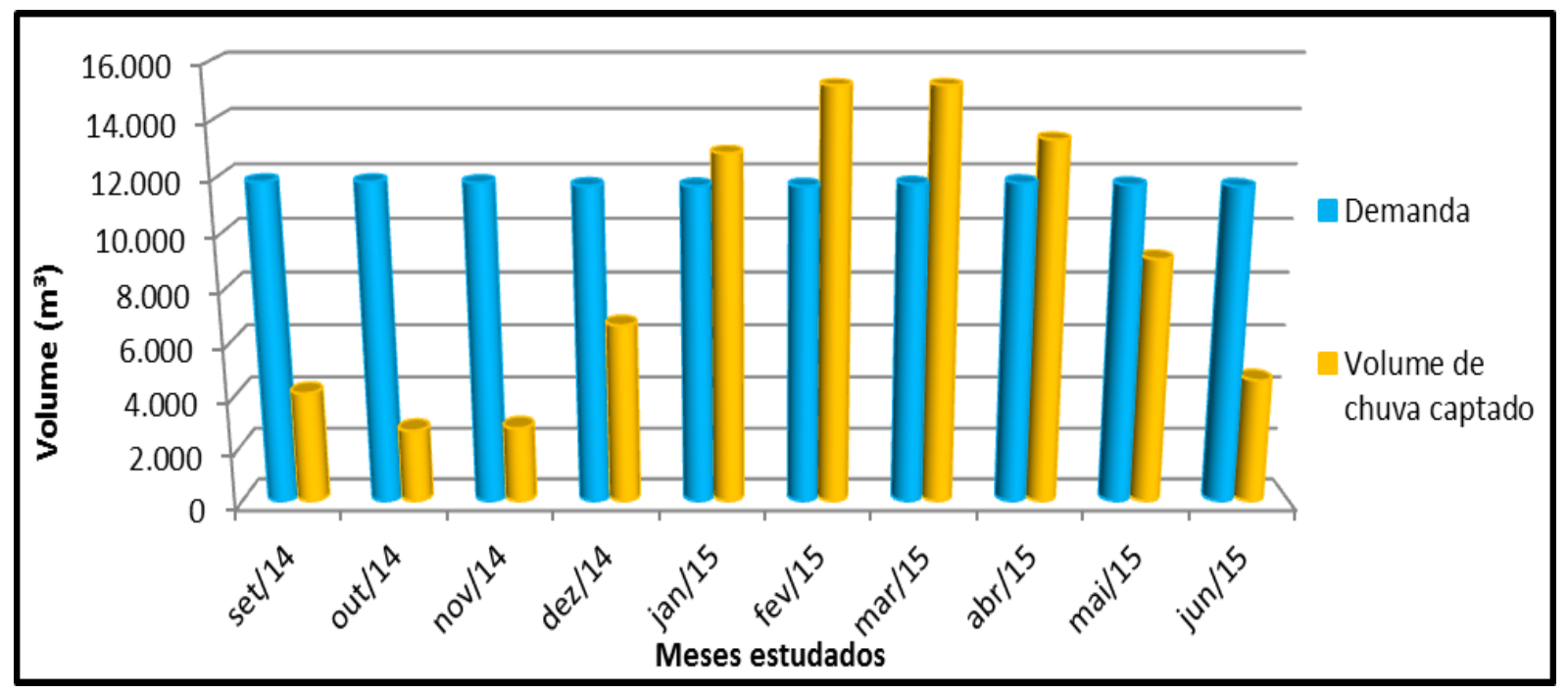

Figura 4 - Balanço hídrico do Setor Básico

Fonte: Autor (2015)

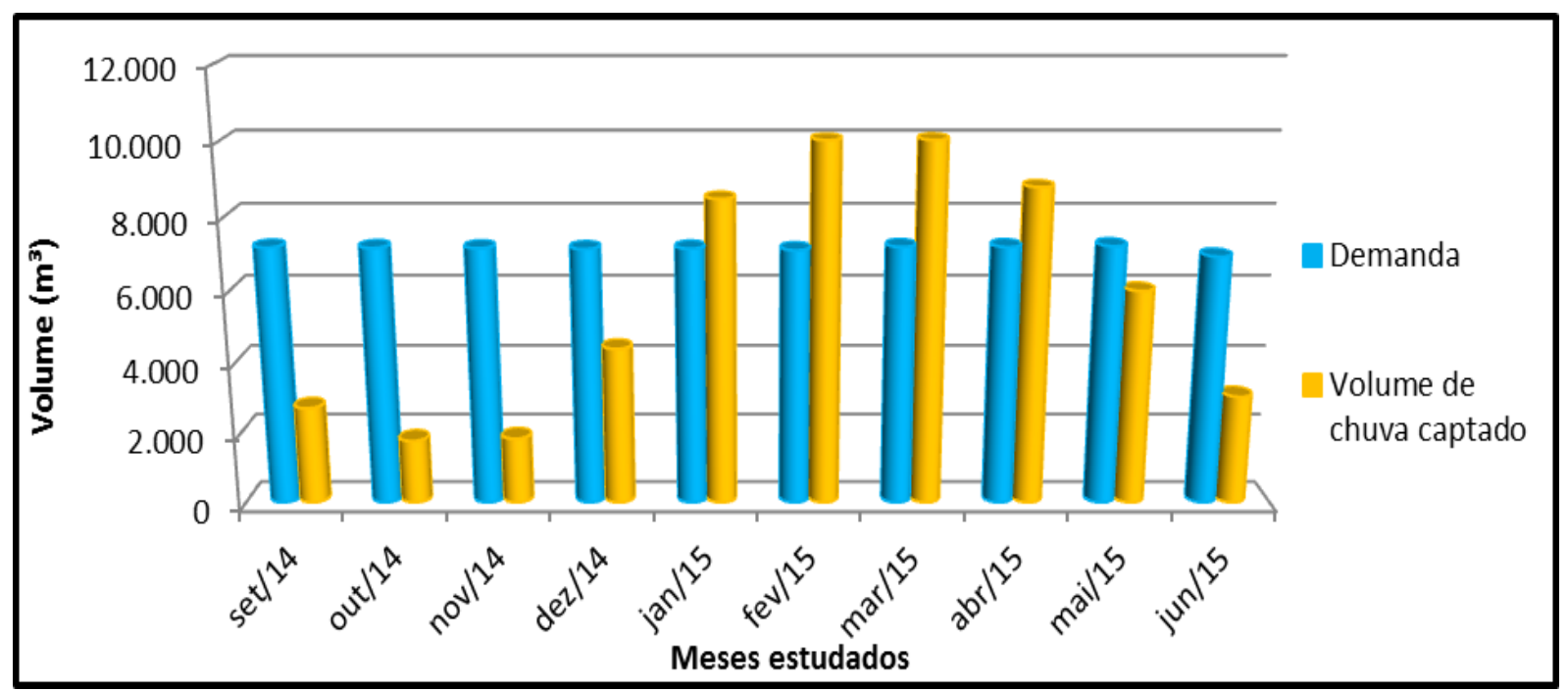

Figura 5 - Balanço hídrico do Setor Profissional

Fonte: Autor (2015) 
Observa-se que nos primeiros meses estudados, que compreenderam os meses de menores índices pluviométricos, a demanda não pode ser atendida totalmente pelo volume de água de chuva aproveitado. Porém, no período de chuva mais intensa, verificado nos meses de Janeiro a Abril, há um aumento significativo no potencial do volume de chuva que pode ser captado, podendo este atender totalmente a demanda de água não potável.

O potencial de economia de água potável pelo uso da água de chuva captada nos Setores Básico e Profissional, pode ser verificado na Figura 6.

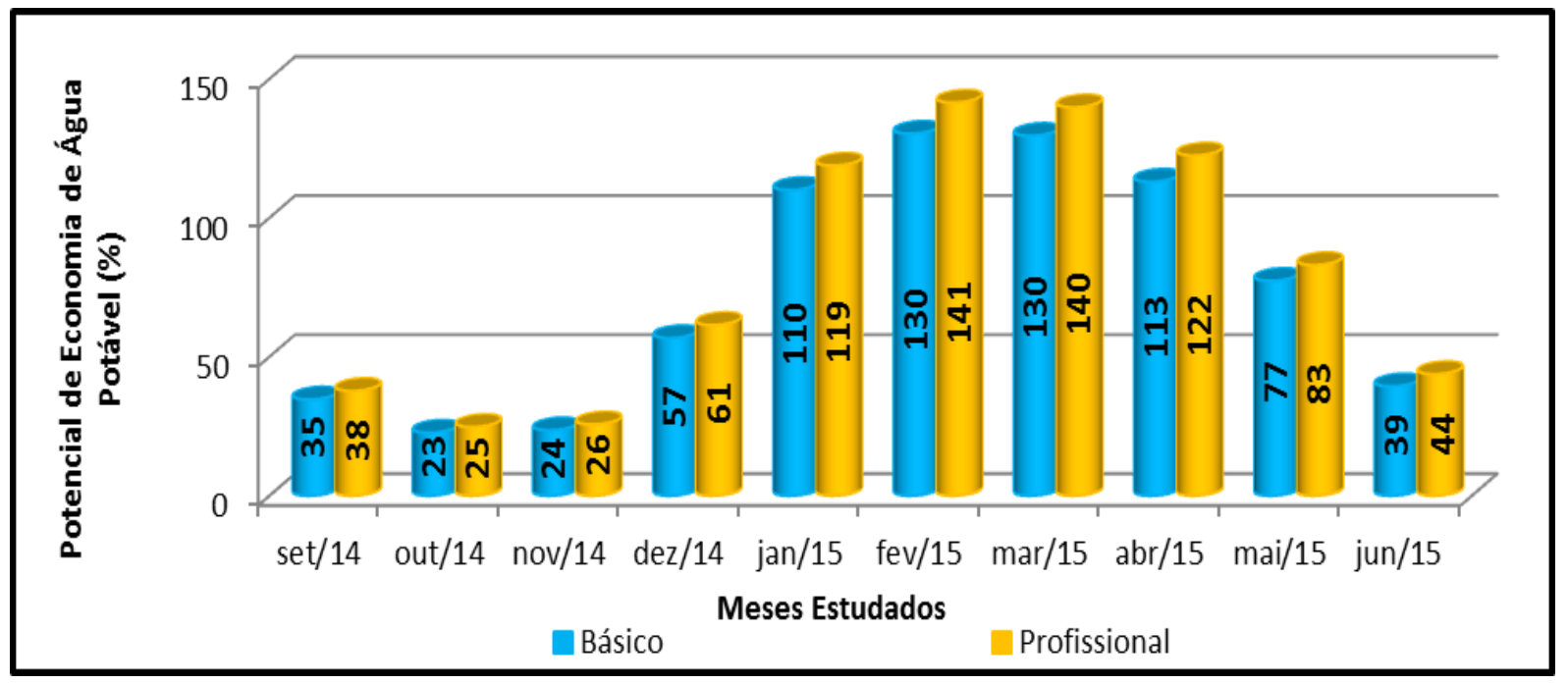

Figura 6 -Potencial de economia de água potável pelo uso de água de chuva

Fonte: Autor (2015)

Nota-se, que por apresentar uma demanda menor, o potencial de economia de água potável é maior no Setor Profissional. No mês de Outubro, mês que apresentou o menor índice pluviométrico, a economia ainda apresentou uma porcentagem de $23 \%$ e $25 \%$ para os Setores Básico e Profissional, respectivamente. Isto mostra que, mesmo nos meses menos chuvosos (Setembro a Novembro), a porcentagem de economia é baixa, porém ainda é considerável. No mês de Dezembro o potencial de economia aumenta, devido ao início do período chuvoso na região, obtendo uma economia acima de $50 \%$ nos dois Setores, e nos meses de Janeiro a Abril apresentou uma economia superior a $100 \%$.

Verifica-se que o potencial de economia de água potável médio obtido foi de $73,8 \%$ para o Setor Básico e 79,9\% para o Setor Profissional. Estes resultados são coerentes aos resultados obtidos por Lima et al. (2011) em que avaliaram o potencial de economia de água potável pelo uso de água de chuva em cidades da região amazônica e verificaram que o potencial da economia de água potável varia entre 21 e 100\%, dependendo da demanda de água potável verificada nas cidades analisadas, com potencial médio de $76 \%$.

Ghisi (2006) avaliou o potencial de economia de água de chuva no setor residencial nas cinco regiões brasileiras. O potencial de economia médio obtido variou de $48 \%$ na região Sudeste e $100 \%$ na região Norte, e nas demais regiões o potencial foi superior a 50\%. Embora este estudo tenha sido feito no setor público, os resultados apresentam similaridade.

Para Bressan e Martini (2005), se o potencial de economia de água tratada para fins não potáveis, através do uso de água de chuva em residências, estiver em torno de $50 \%$, duas alternativas se fazem necessárias: utilizar água proveniente das concessionárias de água tratada para a falta de água de chuva ou aumentar a área de captação de água de chuva.

Como nos três primeiros meses estudados e no mês de junho, o potencial de economia de água tratada foi menor que $50 \%$, isto é, quando a quantidade de água de chuva for insuficiente para atender a demanda, pode-se utilizar da opção de uso da água produzida pela Estação de Tratamento de Água (ETA) da própria universidade. 


\section{CONCLUSÕES}

Neste estudo, investigou-se o potencial de aproveitamento de água de chuva na UFPA, assim como, potencial de economia de água potável. Os resultados mostram que existe um excelente índice pluviométrico na região, o qual favorece o aproveitamento de água de chuva, contribuindo para o uso racional da água e a preservação dos recursos hídricos.

A determinação do consumo de água nas edificações pelo método da Raiz Quadrada nos fornece uma estimativa imprecisa, uma vez que, em comparação aos valores monitorados na micromedição dos banheiros, apresentou valores bem superiores. Esse elevado valor no consumo estimado justifica-se pela grande quantidade de aparelhos com um elevado peso relativo de acordo com a NBR 5626/1988, como é o caso das bacias sanitárias que possuem um peso relativo de 32. Assim, para obter valores estimados mais próximos da realidade, foi determinado um coeficiente de redução.

Em relação ao potencial de aproveitamento de água de chuva, devido aos altos índices pluviométricos e as grandes áreas de captação levantadas nos Setores Básico e Profissional, constatou-se que a UFPA possui potencial real e favorável para utilizar a água de chuva como forma alternativa de abastecimento, em se tratando de termos quantitativos, o qual foi o objetivo desta pesquisa.

Analisando o balanço hídrico entre a demanda de água não potável e o potencial de água de chuva captado mensalmente, verificou-se que ao longo do ano poucos meses a oferta de água de chuva não atende a demanda de água.

Quanto à economia de água potável que poderia haver no sistema da Universidade a partir do uso da água de chuva pra fins não potáveis, apresentou-se baixo no início da pesquisa, porém em relação à alta demanda de água não potável nos banheiros, pode-se considerar essa economia significativa para o sistema da UFPA. Nos meses chuvosos essa economia apresentou porcentagens superiores a $100 \%$, o que demostra ser uma ótima alternativa para o uso sustentável e a gestão e o planejamento dos recursos hídricos na região.

\section{Agradecimentos}

A PROPESP/UFPA pela bolsa de iniciação científica concedida ao primeiro autor através do Programa Institucional de Bolsas PIBIC/UFPA. Agradecimentos especiais aos revisores e colaboradores pela revisão do presente artigo.

\section{Referências}

Associação Brasileira de Normas Técnicas. NBR 5626/1998 - Instalação predial de água fria. Rio de Janeiro (Brasil): ABNT;1998.

Bressan, D. L.; Martini, M. (2005)Avaliação do potencial de economia de água tratada no setor residencial da região sudeste através do aproveitamento de água pluvial [monography]. Florianópolis: Departamento de Engenharia Civil/UFSC.

Conceição, J. S. (2014). Projeto de um sistema para aproveitamento de água da chuva para fins não potáveis no Núcleo de Meio Ambiente (NUMA) da Universidade Federal do Pará (UFPA) Campus Guamá [monography]. Belém: Faculdade de Engenharia Sanitária e Ambiental/UFPA.

Couto, V. B. (2012). Projeto de aproveitamento da água da chuva para o ginásio de esportes da Universidade do Estado de Santa Catarina (UDESC) em Joinville [monography]. Joinville: Departamento de Engenharia Civil/UDESC.

Fasola, G. B. et al (2011). Potencial de economia de água em duas escolas em Florianópolis, SC. Ambiente Construído, 11(4), 65-78. 
Flores, R.A. et al. (2012). Potencial de captação de água de chuva para abastecimento: o caso da cidade de Belém (PA, Brasil). Estudos Tecnológicos em Engenharia, 8(2), 69-80.

Ghisi, E. (2006). Potential for Potable Water Savings by Using Rainwater in the Residential Sector of Brazil. Building and Environment, 41(11), 1544-1550.

Ghisi, E. et al (2007). Rainwater tank capacity and potential for potable water savings by using rainwater in the residential sector of southeastern Brazil. Building and Environment, 42(4), 16541666.

Hagemann, S. E. (2009). Avaliação da qualidade da água da chuva e da viabilidade de sua captação e uso [dissertation]. Santa Maria: Programa de Pós-Graduação em Engenharia Civil/UFSM.

LIMA, J.A. et al. (2011). Potencial da economia de água potável pelo uso de água pluvial: análise de 40 cidades da Amazônia. Revista de Engenharia Sanitária e Ambiental, Rio de Janeiro, 16(3), 291-298

Ortiz, I. A. S. et al. (2009). Potencial de economia de água potável por meio do uso de água pluvial no setor residencial de cidades médias do Estado de São Paulo. In: Anais do $25^{\circ}$ Congresso Brasileiro de Engenharia Sanitária e Ambiental Enfermagem [Internet]; 2009 Setembro 20-25; Recife, Brasil. Available from: http://www.rc.unesp.br/igce/planejamento/download/rodrigo/potencial.pdf

Portéglio, L. O. (2013)Avaliação do consumo de água a Cidade Universitária Professor José da Silveira Netto - destacando dois banheiros coletivos do Setor Básico e Profissional - Belém-PA. Relatório Final de Iniciação Científica. Belém.

Silva, R. A. et al. (2013). Potencial de uso de água de chuva para abastecimento: o Campus Básico da UFPA - Belém. In: Anais do $20^{\circ}$ Simpósio de Recursos Hídricos, 2013 Novembro 17-22; Bento Gonçalves/RS, Brasil.

Sistemas de Informacão Hidrológicas - HIDROWEB. Agência Nacional de Águas (2014). Série Histórica de Chuvas de Belém. Available from: http://hidroweb.ana.gov.br.

Tomaz, P (2003). Aproveitamento de água de chuva para áreas urbanas e fins não potáveis. São Paulo: Navegar Editora.

Universidade Federal do Pará/UFPA (2014). Planta arquitetônica da Cidade Universitária José da Silveira Netto. Prefeitura do Campus, Belém.

Yoshino, G. H.(2012). O aproveitamento de água de chuva para fins não potáveis na Cidade Universitária Professor José da Silveira Netto - Belém/PA [dissertation]. Belém: Programa de PósGraduação em Engenharia Civil/UFPA. 